\title{
PARTICIPAÇÃO DO SETOR FLORESTAL NOS INDICADORES SOCIOECONÔMICOS DO ESTADO DO ESPÍRITO SANTO ${ }^{1}$
}

\author{
Sebastião Renato Valverde ${ }^{2}$, Gilca Garcia de Oliveira ${ }^{3}$, Thelma Shirlen Soares ${ }^{4}$ e Rosa Maria Armond \\ Miranda Carvalho ${ }^{4}$
}

\begin{abstract}
RESUMO - O objetivo deste estudo foi avaliar a importância do setor florestal para o desenvolvimento do Estado do Espírito Santo, através de sua participação e dos seus multiplicadores de impacto nos indicadores sociais e econômicos, como na constituição do valor da produção, na geração de empregos e rendas, na arrecadação de impostos e na formação de divisas oriundas do saldo da balança comercial. Foram empregados modelos econômicos de equilíbrio geral, através da análise da Matriz de Insumo-Produto. Os resultados indicaram que o setor florestal é importante para o desenvolvimento social e econômico desse estado, tanto na contribuição dos indicadores quanto na dos multiplicadores de impacto da economia.
\end{abstract}

Palavras-chave: Economia florestal, modelos econômicos de equilíbrio geral multissetoriais e planejamento florestal.

\section{PARTICIPATION OF THE FOREST SECTOR IN THE SOCIOECONOMIC INDICATORS OF THE STATE OF ESPÍRITO SANTO}

\begin{abstract}
The objective of this study was to evaluate the importance of the forestry sector on the development of the State of Espirito Santo through its participation and impact multiplier on social and economical indicators such as the generation of production value, jobs and income, taxes and exchange value derived from the trade balance. The results showed the importance of the forest sector on the social and economical development of the State, in its contribution of indicators as well as on impact multipliers in the economy.
\end{abstract}

Key words: Forestry economy, multisector general economic equilibrium models and forestry planning.

\section{INTRODUÇÃO}

O momento que se vivencia no Brasil é marcado por uma conjugação de esforços de diferentes atores sociais na busca por um modelo de desenvolvimento que propicie melhor distribuição de renda e condições dignas de sobrevivência a cada cidadão.

Atualmente, pode-se constatar o reconhecimento mundial da vocação da atividade florestal para a sustentabilidade e a significativa contribuição do setor florestal para o desenvolvimento regional e, ou, setorial.

Nesse contexto, vale ressaltar a potencialidade das florestas brasileiras e a importância do setor florestal para o país, pois ele pode proporcionar melhorias nos indicadores macroeconômicos de bem-estar social, bem como o aumento na produção, na geração de empregos e rendas, na arrecadação de impostos, na

\footnotetext{
${ }^{1}$ Recebido em 10.12.2003 e aceito para publicação em 25.11.2004.

${ }^{2}$ Departamento de Engenharia Florestal da Universidade Federal de Viçosa. Viçosa, MG. E-mail: <valverde@ufv.br>.

${ }^{3}$ Departamento de Ciências Sociais Aplicadas à Agricultura da Universidade Federal da Bahia. Cruz das Almas, BA.

4 Programa de Pós-Graduação em Ciência Florestal da Universidade Federal de Viçosa. Viçosa, MG.
} 
formação de divisas e na melhoria das contas nacionais (CARVALHO et al., 2003).

No que se refere aos indicadores econômicos, o setor florestal brasileiro contribui com, aproximadamente, 4,5\% do PIB, emprega mais de 2 milhões de trabalhadores, além de recolher impostos e divisas de exportações, contribuindo para melhorias na balança comercial (SIQUEIRA, 2002).

De fato, as atividades florestais e agrícolas e suas indústrias correlatas possuem a propriedade de promover o desenvolvimento graças às suas relações intersetoriais na economia.

Especificamente no Estado do Espírito Santo, o setor florestal merece destaque, pois, devido às suas características naturais e físicas, sua vocação para as atividades agrícolas e florestais e sua infra-estrutura, o Estado tem todas as condições necessárias para favorecer a promoção do desenvolvimento socioeconômico, por meio da alavancagem dessas atividades (SCHETTINO et al., 2000; AGÊNCIA ..., 2002).

As condições naturais favoráveis, aliadas ao desenvolvimento tecnológico avançado da silvicultura e a outras condições privilegiadas, como localização geográfica, infra-estrutura, logística de transporte e diversificação de plantas industriais, entre outras, permite ao Estado um elevado potencial de crescimento da atividade florestal, o que lhe assegura um papel de destaque no desenvolvimento capixaba, como um dos seus principais vetores de desenvolvimento.

O Estado do Espírito Santo acompanha essa evolução, possuindo atualmente cerca de 189.850 ha de florestas plantadas, utilizadas para os diversos fins (celulose, fabricação de móveis, caixas, artefatos para construção civil e carvão, entre outros), que movimentam R \$ 3,0 bilhões/ano, equivalentes a $15 \%$ do PIB estadual e geram 60 mil empregos diretos e indiretos. Somente no setor de produção, via integração produtor-indústria e plantios próprios de agricultores, estima-se que estejam envolvidas cerca de 14.000 propriedades rurais, a maioria de base familiar, que têm nessa atividade uma importante alternativa de renda, especialmente em períodos cíclicos de preços baixos do café, principal atividade agrícola do Estado (INCAPER, 2004).

Assim, este estudo teve como objetivo avaliar a importância do setor florestal capixaba para a promoção do desenvolvimento socioeconômico do Estado do
Espírito Santo, através da participação nos indicadores macroeconômicos.

\section{MATERIAL E MÉTODOS}

\subsection{Fonte de dados}

Para este estudo foram utilizados dados que constam das Tabelas de Coeficientes de Insumo-Produto inclusos no Sistema de Contas Nacionais (SCN) do Instituto Brasileiro de Geografia e Estatística (IBGE), que descrevem as relações multissetoriais entre insumos e produtos para uma economia específica.

Esses valores são facilmente encontrados para representar o cenário econômico das nações, no entanto, em termos regionais, alguns ajustes são necessários para que se estabeleçam as relações setoriais definidas matricialmente. Assim, utilizaram-se para a execução deste trabalho as Tabelas de Recursos de Bens e Serviços e de Consumo Intermediário em caráter nacional para posteriormente, por meio de proporcionalidades e ajustamentos, serem estabelecidas as relações estaduais.

A partir desses dados, montou-se a matriz de insumo-produto nacional para o ano de 1999, bem como os dados regionais de valores de compra, venda, exportação e importação, e elaborou-se a matriz estadual, através de ajustes e proporcionalidades, conforme Haddad (1976).

Para facilitar as análises, as atividades e os produtos foram agregados em 11 setores, conforme apresentado no Quadro 1.

\subsection{Matriz insumo-produto}

A Matriz Insumo-Produto (MIP) representa o lado produtivo da economia com suas relações intersetoriais. É uma adaptação simplificada do modelo neoclássico de equilíbrio geral, especialmente do modelo walrasiano (SACHS e LARRAIN, 1998). As colunas representam as despesas, enquanto as linhas mostram as receitas. Para o caso da economia capixaba, algumas incorporações e ajustes devem ser definidos, como mostrado no Quadro 2.

As tabelas, quando designadas com subescrito $B R$, indicam que elas foram obtidas dos dados nacionais; $E S$ indica que os dados contêm certa proporcionalidade ou originalidade com os dados estaduais, e, quando não existe indicação, os dados que formam a matriz são, exclusivamente, de origem estadual. A tabela $V_{B R}$ 
é originária da Tabela de Recursos de Bens e Serviços, que fornece informações sobre a origem setorial de bens e serviços da economia, enquanto a tabela $U_{B R}$ é originária da Tabela de Consumo Intermediário, que indica as relações de demanda e de oferta de bens e serviços da economia brasileira.

A matriz $\mathrm{Z}$ representa as transações intersetoriais, onde estão definidos a demanda e o consumo setorial intermediário. Foi construída em termos de Brasil, e, posteriormente, estabeleceram-se relações com a estrutura estadual. A matriz M contém as importações do estado e foi subdividida em importações do Brasil e importações do exterior. Para o cálculo da matriz de valor adicionado $\mathrm{W}$, utilizaram-se os dados nacionais e foram elaboradas as proporções estaduais de acordo com o consumo intermediário capixaba. A matriz X corresponde a produção por setor e $\mathrm{Q}$, a produção por produto.

A demanda final $\mathrm{Y}$ foi montada de acordo com a disponibilidade dos dados regionais. A parcela correspondente às exportações $\left(\mathrm{E}_{\mathrm{BR}}\right)$ foi subdividida em exportações do Brasil e exportações para o exterior, com dados originais do estado. A variação do estoque foi calculada por meio de dados estaduais. No entanto, a parcela correspondente ao consumo das famílias e do governo e à formação bruta de capital fixo foi obtida proporcionalmente aos dados nacionais.

A partir dessas tabelas de efeito nacional, foi calculada a matriz nacional (estabelecida por proporcionalidade entre os valores de consumo intermediário nacional e estadual), bem como a matriz de coeficientes técnicos de insumos diretos e indiretos para o Estado do Espírito Santo.

\section{RESULTADOS E DISCUSSÕES}

Analisando a participação no valor e relação das compras dos setores produtivos do estado, observouse que o setor florestal, apesar de adquirir a maior parte de seus insumos em outros estados do Brasil, apresenta significativa demanda dentro do próprio estado, principalmente no que tange à demanda por produtos oriundos das propriedades rurais, ou seja, madeira proveniente dos programas de fomento florestal da única indústria de celulose do Estado. Dos 11 setores analisados, verificou-se que o florestal foi o sexto maior a demandar insumos produzidos domesticamente e o quarto na demanda de produtos vindos do meio rural capixaba, conforme mostrado no Quadro 3.

As compras de insumos, oriundas de outros estados brasileiros, realizadas pelo setor florestal estão relacionadas, principalmente, com madeira vinda do Estado da Bahia. Certamente, este valor poderia ser menor caso houvesse incremento na área reflorestada no Espírito Santo, o que acarretaria aumento no valor da produção do estado, na geração de empregos, salários e impostos.

Quadro 1 - Agregação das atividades em setores

Table 1-Aggregation of the activities in sectors

\begin{tabular}{ll}
\hline Setor & \multicolumn{1}{c}{ Atividades } \\
\hline Agricultura & Agropecuária \\
\hline Mineração & Extrativa mineral; Extração de petróleo e gás \\
\hline Metalsiderúrgico & Minerais não-metálicos; Siderurgia; Metalurgia não-ferrosos \\
\hline Maquinários & $\begin{array}{l}\text { Outros metalúrgicos; Máquinas e tratores; Material elétrico; Equipamentos eletrônicos; Automóveis, } \\
\text { caminhões e ônibus; Outros veículos e peças }\end{array}$ \\
\hline Florestal & Madeira e mobiliário; Papel e gráfica; Indústria da borracha \\
\hline Plástico & Artigos de plástico \\
\hline Petroquímicos & Elementos químicos; Refino do petróleo; Químicos diversos; Farmacêutica e de perfumaria \\
\hline Têxteis & Indústria têxtil; Artigos do vestuário; Fabricação de calçados \\
\hline Alimentícios & $\begin{array}{l}\text { Indústria do café; Beneficiamento de produtos vegetais; Abate de animais; Indústria de laticínios; } \\
\text { Indústria de açúcar; Fabricação de óleos vegetais; Outros produtos alimentares }\end{array}$ \\
\hline Diversos & Indústrias diversas \\
\hline Serviços & $\begin{array}{l}\text { Serviços industriais de utilidade pública; Construção civil; Comércio; Transportes; Comunicações; } \\
\text { Instituições financeiras; Serviços prestados às famílias; Serviços prestados às empresas; Aluguel } \\
\text { de imóveis; Administração pública; Serviços privados não-mercantis }\end{array}$ \\
\hline
\end{tabular}

Fonte: Preparado pelos autores. 
Quadro 2 - Relações de insumo-produto usados na construção da matriz para o Estado do Espírito Santo

Table 2 -Relationships of input-output used in the matrix of the State of Espírito Santo

\begin{tabular}{|c|c|c|c|c|}
\hline Variáveis & Produto & Setor & $\begin{array}{c}\text { Demanda } \\
\text { Final } \\
\end{array}$ & $\begin{array}{c}\text { Produto } \\
\text { Total } \\
\end{array}$ \\
\hline Produto & & $\mathrm{U}_{\mathrm{BR}}$ & $\mathrm{E}_{\mathrm{BR}}$ & $\mathrm{Q}_{\mathrm{BR}}$ \\
\hline Setor & $\mathrm{V}_{\mathrm{BR}}$ & $\mathrm{Z}_{\mathrm{BR}}\left(\mathrm{Z}_{\mathrm{ES}}\right)$ & $\mathrm{Y}_{\mathrm{BR}}\left(\mathrm{Y}_{\mathrm{ES}}\right)$ & $\mathrm{X}_{\mathrm{ES}}$ \\
\hline Importações & & $\mathrm{M}_{\mathrm{ES}}$ & & \\
\hline Valor adicionado & & $\mathrm{W}_{\mathrm{BR}}\left(\mathrm{W}_{\mathrm{ES}}\right)$ & & \\
\hline Insumo Total & $\mathrm{Q}_{\mathrm{BR}}^{\prime}$ & $\mathrm{X}_{\mathrm{ES}}^{\prime}$ & & \\
\hline
\end{tabular}

Considerando o peso que o setor serviços tem no estado, devido às suas atividades portuárias, de comércio, transporte e turismo, além de considerar o seu papel como auxiliar dos demais setores produtivos, fez-se uma comparação gráfica (Figuras 1, 2 e 3) para verificar a importância dos outros setores sem a participação de serviço.

Na Figura 1, mostra-se quanto o setor florestal é importante como consumidor de insumos produzidos no próprio estado, como madeira e produtos químicos utilizados na produção de celulose. Nesse caso, ao retirar os dados de serviços, o setor florestal representa $5 \%$ do consumo intermediário doméstico.

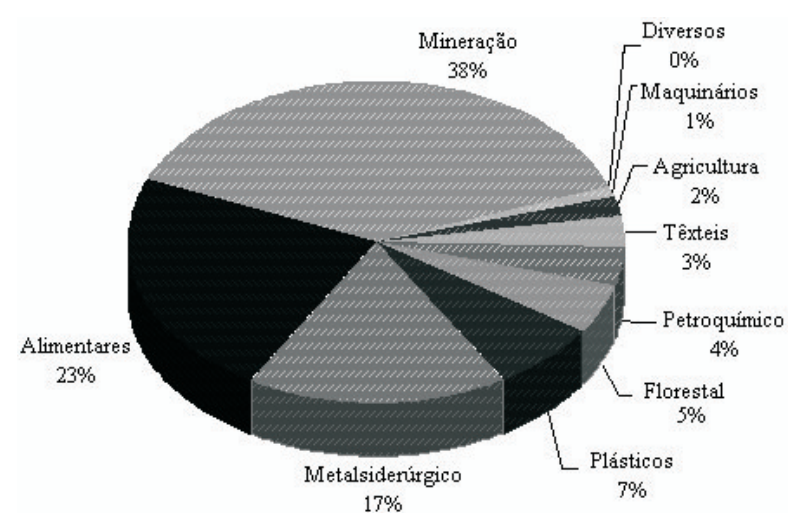

Figura 1 - Valor das compras domésticas dos setores produtivos, sem serviço, em 1999.

Figure 1 - Value of the domestic purchases of the productive sectors, without service, in 1999.

Porcentualmente, o setor florestal é responsável por $1,64 \%$ da demanda de insumos produzidos domesticamente e $2,20 \%$ dos oriundos das propriedades rurais, sendo apenas a indústria de celulose responsável por 76,32 e 81,72\%, respectivamente, dessas demandas, indicando quanto ela é significativa para o setor e o quanto ambos, indústria de celulose e setor florestal, são importantes para a economia do Estado (Quadro 4).

Quadro 3 - Valor das compras realizadas pelos setores produtivos do Estado do Espírito Santo, em 1999

Table 3 - Value of the purchases accomplished by the productive sectors of the State of Espírito Santo, in 1999

\begin{tabular}{lrrrr}
\hline Setor & \multicolumn{3}{c}{ Valor das Compras dos Setores $(\mathrm{R} \$ \mathrm{x}$} & $\left.10^{6}\right)^{*}$ \\
\hline Agricultura & No Estado & Dos Produtores do Estado & Do Resto do Brasil & Do Resto do Mundo \\
Mineração & 38859,45 & 4264,79 & 17414,24 & 0,24 \\
Metalsiderúrgico & 587273,23 & 680,95 & 1134243,08 & 48734,97 \\
Maquinários & 274929,95 & 3666,97 & 455677,85 & 257827,69 \\
Florestal & 17054,81 & 61,73 & 48191,62 & 1486,52 \\
Plástico & 78076,23 & 16456,66 & 184832,58 & 7553,58 \\
Petroquímico & 108796,04 & - & 21,07 & 47042,86 \\
Têxteis & 58865,42 & 21582,71 & 67340,96 & 47452,61 \\
Alimentares & 43017,59 & 5,58 & 184925,91 & 897,49 \\
Diversos & 363456,87 & 50756,63 & 357395,84 & 30725,55 \\
Serviços & 4204,35 & - & 10804,31 & 151,68 \\
\hline Total & 3197832,72 & 650427,54 & 4869852,23 & 4925969,01 \\
\hline Madeireiro & 4772366,64 & 747903,56 & 7330699,69 & 5367842,19 \\
Celulose e Papel & 16589,96 & 357,80 & 70119,41 & 3293,27 \\
Borracha & 60336,22 & 13448,08 & 114713,17 & 3383,61 \\
Florestal & 1150,06 & 2650,77 & - & 876,71 \\
\hline
\end{tabular}

$* \mathrm{US} \$ 1,00=\mathrm{R} \$ 1,81$.

R. Árvore, Viçosa-MG, v.29, n.1, p.105-113, 2005 
Quadro 4 - Participação do setor florestal na economia do Estado do Espírito Santo (ES), em 1999 Table 4-Participation of the forest sector in the economy of the State of Espírito Santo (ES), in 1999

\begin{tabular}{lccc}
\hline \multirow{2}{*}{ Variáveis } & \multirow{2}{*}{ Setor } & \multicolumn{2}{c}{\begin{tabular}{c} 
Participação (\%) \\
\cline { 3 - 4 }
\end{tabular}} \\
\cline { 3 - 4 } ICMS & & $\begin{array}{c}\text { Do Setor Florestal } \\
\text { no ES }\end{array}$ & $\begin{array}{c}\text { Da Indústria de Celulose no } \\
\text { Setor Florestal }\end{array}$ \\
\hline Compras & Domésticas & 1,00 & 11,98 \\
& Produtores rurais do ES & 1,64 & 76,32 \\
& Resto do Brasil & 2,20 & 81,72 \\
& Resto do mundo & 2,52 & 60,12 \\
\hline Vendas & Domésticas & 0,13 & 4,35 \\
& Resto do Brasil & 0,74 & 2,67 \\
& Resto do mundo & 1,58 & 41,34 \\
\hline Produção & & 18,07 & 99,81 \\
\hline
\end{tabular}

Outro ponto importante, e que será discutido na parte de comércio exterior, é com relação às compras de outros países, indicando que o setor consome apenas $0,13 \%$ do total, sendo a indústria de celulose responsável por apenas $4,13 \%$ desse total. Isso mostra quanto o setor florestal capixaba está voltado para o mercado local, no que tange à demanda de matéria-prima, e para o mercado internacional, quanto à venda de produtos.

As vendas do setor florestal capixaba para o mercado internacional representam $18,07 \%$ do total do estado, sendo apenas a indústria de celulose responsável por praticamente toda essa participação. Nesse caso, o setor florestal se apresenta como o quarto maior exportador do estado, antecedido pelos setores: serviços, mineração (representado pela exportação do minério de ferro pelotizado) e metalsiderúrgico.

Na Figura 2, mostra-se o valor das vendas domésticas dos setores produtivos do estado, excluindo o de serviço. Nota-se, nessa figura,que o setor florestal apresenta também uma participação significativa nesse mercado, mesmo sabendo que a maior indústria do setor direciona seus produtos para o mercado internacional.

Pelo Quadro 5, nota-se que o setor florestal é o quarto maior no valor da produção total do estado, representando quase $5 \%$ desse total, em que apenas a indústria de celulose é responsável por $86,32 \%$ do total do setor florestal.

\subsection{Comércio exterior}

Neste tópico do trabalho, consideraram-se, tanto para as exportações quanto para as importações, todas as relações de comércio, venda e compra com o mercado internacional que os setores produtivos do Estado do Espírito Santo realizam. A princípio, observou-se que o estado apresentou, em 1999, balança comercial superavitária ( $\mathrm{R} \$ 1.697 .503 .396)$, sendo os principais setores responsáveis, em ordem crescente, metalsiderúrgico, mineração e florestal, e os únicos com déficit foram serviços e maquinário, conforme indicado no Quadro 6.

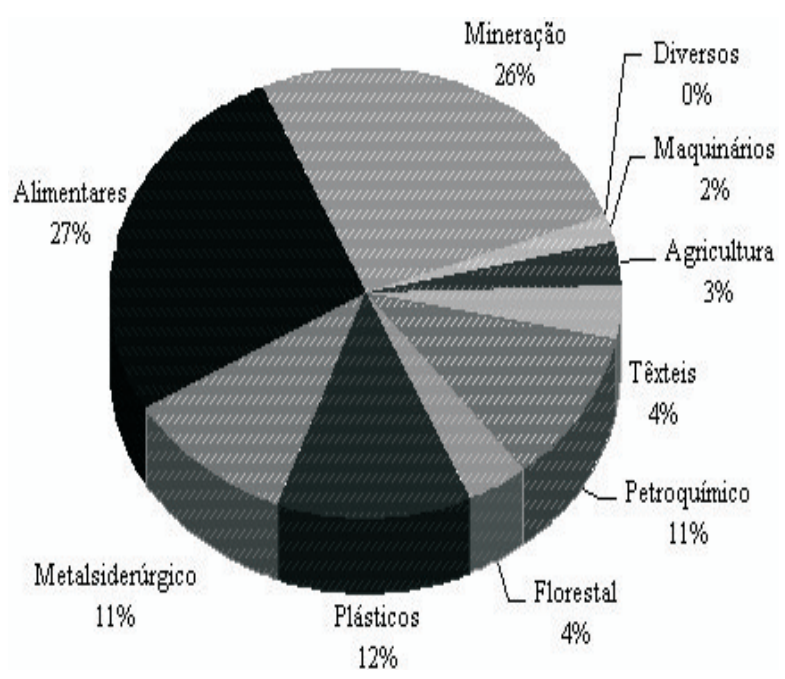

Figura 2 - Participação dos setores produtivos nas vendas domésticas, sem serviço, 1999.

Figure 2 - Participation of the productive sectors in domestic sales, without service, in 1999.

R. Árvore, Viçosa-MG, v.29, n.1, p.105-113, 2005 
Quadro 5 - Valores das vendas para o próprio estado, para os outros estados do Brasil e para o exterior, da variação de estoque e da produção dos setores produtivos do Estado do Espírito Santo, em 1999

Table 5 -Values of sales for the state istself, in the other states of Brazil and for the exterior, of the stock variation and of the production of the productive sectors of the State of Espirito Santo, in 1999

\begin{tabular}{|c|c|c|c|c|c|}
\hline \multirow[t]{2}{*}{ Setor } & \multicolumn{3}{|c|}{ Valor das Vendas dos Setores $\left(\mathrm{R} \$ \mathrm{x} 10^{6}\right)$} & \multirow{2}{*}{$\begin{array}{c}\text { Variação } \\
\text { de Estoque }\end{array}$} & \multirow{2}{*}{$\begin{array}{c}\text { Valor } \\
\text { da Produção } \\
\end{array}$} \\
\hline & No Estado & No Resto do Brasil & No Resto do Mundo & & \\
\hline Agricultura & 65,33 & 29,42 & 15,69 & 1,73 & 112,16 \\
\hline Mineração & 511,27 & 781,79 & 1389,42 & 274,07 & 2956,56 \\
\hline Metalsiderúrgico & 211,47 & 288,98 & 1595,23 & $-34,95$ & 2060,73 \\
\hline Maquinários & 39,67 & 48,41 & 0,03 & 0,98 & 89,09 \\
\hline Florestal & 75,31 & 152,97 & 1002,42 & 2,34 & 1222,44 \\
\hline Plástico & 224,27 & 13,57 & 213,99 & 0,78 & 6,72 \\
\hline Petroquímico & 213,52 & 156,12 & 17,96 & $-0,05$ & 387,56 \\
\hline Têxteis & 71,62 & 240,49 & 9,20 & 17,44 & 338,75 \\
\hline Alimentares & 521,34 & 437,82 & 84,13 & 20,57 & 1063,86 \\
\hline Diversos & 7,28 & 3,45 & 12,18 & 1,08 & 23,99 \\
\hline Serviços & 8027,26 & 7465,02 & 1400,78 & 287,80 & 17180,86 \\
\hline Total & 9968,35 & 9618,01 & 5741,04 & 571,80 & 25442,72 \\
\hline Madeireiro & 51,27 & 86,37 & 1,90 & 4,60 & 144,14 \\
\hline Celulose e Papel & 19,15 & 64,86 & 996,34 & $-2,26$ & 1078,08 \\
\hline Borracha & 4,89 & 1,74 & 4,19 & - & 0,22 \\
\hline Total Florestal & 75,31 & 152,97 & 1002,42 & 2,34 & 1222,44 \\
\hline
\end{tabular}

$* \mathrm{US} \$ 1,00=\mathrm{R} \$ 1,81$.

Nota-se, no Quadro 6, que o setor florestal foi o quarto maior exportador, ou seja, $8,13 \%$ do total, contrastando favoravelmente com as importações, em que foi responsável por apenas $1,52 \%$ do total. Praticamente, a indústria de celulose é a única representante desse setor no comércio internacional, no que tange às exportações, mas, no caso das importações, já se denotou ser expressiva a participação da indústria de madeira e mobiliário, como também, implicitamente, as importações das atividades de impressão de jornais, na aquisição de papéis e bens de capital. Dessa forma, os resultados comprovam que o setor florestal capixaba é predominantemente representado pela indústria de celulose, sendo esta voltada exclusivamente para o mercado internacional.

\subsection{Indicadores sociais e econômicos}

O Estado do Espírito Santo, apesar de sua pequena extensão, apresenta uma economia bastante vigorosa e participativa na formação dos indicadores econômicos brasileiros.

Pelo Quadro 7, observa-se que o PIB do estado em 1999 foi da ordem de pouco mais de R \$ 22 bilhões, sendo o setor florestal responsável por aproximadamente $4 \%$ deste total. Assim como no valor da produção bruta, os setores que mais contribuíram para a formação do PIB foram, em ordem crescente, serviços, metalsiderúrgico, mineração e florestal, enquanto os menores: diversos e agricultura. A agroindústria (setor alimentício) capixaba tem também participação significativa no PIB, vindo logo após o florestal.

Com relação a empregos, o setor florestal também apresentou números significativos: quarto maior colocado, antecedido apenas pelos setores serviços, têxteis e alimentícios. É importante destacar que, além de ser um setor intensivo em mão-de-obra, ele é constituído por uma peculiaridade que o distingue de muitos outros, que é a geração de empregos tanto nas indústrias quanto no meio rural, graças à atividade de reflorestamento, como a implantação, manutenção e colheita florestal.

O setor florestal se destaca significativamente nas remunerações salariais, apresentando a segunda maior colocação. Isso indica que, além da natureza intrínseca de gerar um número elevado de empregos, a indústria florestal, principalmente a de celulose, remunera bem a sua mão-de-obra. 
Quadro 6 - Valor das exportações, importações e balança comercial com o resto do mundo e respectivos porcentuais dos setores produtivos do Estado do Espírito Santo, em 1999

Table 6 -Value of exports, imports and trade balance with the rest of the world and respective percentile of the productive sectors of the State of Espírito Santo, in 1999

\begin{tabular}{|c|c|c|c|c|c|c|}
\hline$\overline{\text { Setor }}$ & $\begin{array}{c}\text { Exportações } \\
\left(\operatorname{RS} \times 10^{6}\right)^{*}\end{array}$ & $\%$ & $\begin{array}{c}\text { Importações } \\
\left(\operatorname{RS} \times 10^{6}\right)^{*}\end{array}$ & $\%$ & $\begin{array}{c}\text { Balança comercial } \\
\left(\mathrm{RS} \times 10^{6}\right)^{*}\end{array}$ & $\%$ \\
\hline$\overline{\text { Agricultura }}$ & 45,11 & 0,32 & 17,41 & 0,14 & 27,69 & $\overline{1,63}$ \\
\hline Mineração & 2171,21 & 15,29 & 1182,98 & 9,46 & 988,24 & 58,22 \\
\hline Metalsiderúrgico & 1884,20 & 13,27 & 713,51 & 5,71 & 1170,70 & 68,97 \\
\hline Maquinários & 48,44 & 0,34 & 49,68 & 0,40 & $-1,24$ & $-0,07$ \\
\hline Florestal & 1155,39 & 8,13 & 192,39 & 1,54 & 963,01 & 56,73 \\
\hline Plástico & 227,55 & 1,60 & 47,06 & 0,38 & 180,49 & 10,63 \\
\hline Petroquímico & 174,08 & 1,23 & 114,79 & 0,92 & 59,29 & 3,49 \\
\hline Têxteis & 249,68 & 1,76 & 185,82 & 1,49 & 63,86 & 3,76 \\
\hline Alimentares & 521,95 & 3,67 & 388,12 & 3,10 & 133,83 & 7,88 \\
\hline Diversos & 15,63 & 0,11 & 10,96 & 0,09 & 4,67 & 0,28 \\
\hline Serviços & 8865,80 & 62,42 & 9795,82 & 78,33 & $-930,02$ & $-54,79$ \\
\hline Total & 14203,66 & 100,00 & 12506,16 & 100,00 & 1697,50 & 100,00 \\
\hline Madeira mobiliário & 88,27 & 7,64 & 73,41 & 38,16 & 14,86 & 1,54 \\
\hline Celulose e papel & 1061,19 & 91,85 & 118,10 & 61,39 & 943,09 & 97,93 \\
\hline Borracha & 5,93 & 0,51 & 0,88 & 0,46 & 5,06 & 0,53 \\
\hline Florestal & 1155,39 & 100 & 192,39 & 100 & 963,01 & 100,00 \\
\hline
\end{tabular}

* US\$1,00 = R \$1,81.

Um fato que surpreende no Quadro 7 é o baixo valor do número de empregos formais no estado (521.010), principalmente na agricultura (7.213), no ano de 1999. Para uma população de cerca de 3 milhões de habitantes, isso significa que ou havia uma taxa de desemprego elevada e, ou, um grande número de trabalhadores no mercado informal. Segundo dados da Pesquisa Nacional

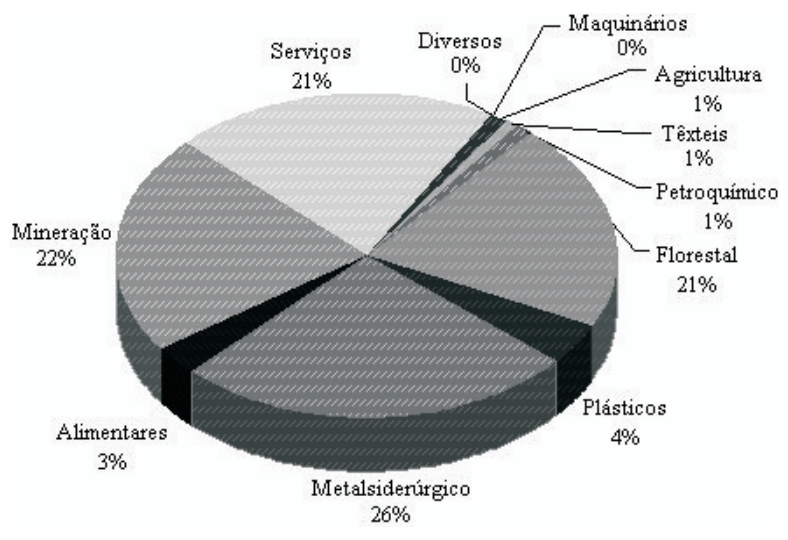

Figura 3 - Balança comercial dos setores econômicos capixabas, 1999.

Figure 3 - Trade balance of the State of Espírito Santo economic sectors, in 1999. por Domicílios (PNAD), o número de pessoas ocupadas no estado naquele ano era de aproximadamente 1,4 milhão e somente na agricultura existiam quase 440 mil pessoas trabalhando.

O que acontece na agricultura capixaba não é diferente do que ocorre no restante do país, ou seja, grande parte da mão-de-obra no campo é informal; trabalham-se em regime de produção de parcerias, empreitadas, diaristas, empregando crianças, mulheres e idosos com remunerações inferiores a um salário mínimo mensal, além de mão-de-obra familiar, muitas vezes, não remunerada.

Essa informalidade tende a subestimar os multiplicadores e os índices de participação da agricultura, como também dos setores florestal e alimentícios fortemente relacionados com ela, nos indicadores de emprego e remunerações.

Ao que tudo indica, boa parte do emprego e a respectiva remuneração gerada quando aumentadas as áreas de reflorestamentos nas propriedades rurais para atender ao consumo das indústrias florestais. Pressupõe-se que, com a adição dos dados de empregos informais, os indicadores referentes a emprego, no setor florestal, seriam mais representativos da realidade. Isso só vem reforçar o setor como fundamental na geração

R. Árvore, Viçosa-MG, v.29, n.1, p.105-113, 2005 
de empregos, no campo e na cidade, contribuindo enormemente para a redução do desemprego e do êxodo rural.

Retornando à análise do Quadro 7, o pior desempenho do setor florestal foi relacionado à arrecadação de impostos, responsabilizando-se por apenas $1,00 \%$ do total arrecadado de ICMS. Isso se deve ao fato de que os produtos florestais são, na sua maioria, classificados como produtos básicos ou semi-elaborados que, por naturezas fiscal e tributária, são menos taxados que os produtos com maior grau de processamento e os supérfluos.

Quadro 7 - Indicadores sociais e econômicos dos setores produtivos do Estado do Espírito Santo, em 1999 Table 7 - Social and economic indicators of the productive sectors of the State of Espírito Santo, in 1999

\begin{tabular}{|c|c|c|c|c|c|c|c|c|}
\hline Setor & $\begin{array}{c}\text { PIB } \\
\left(\mathrm{RS} \times 10^{6}\right)^{*}\end{array}$ & $\%$ & $\begin{array}{c}\text { Emprego } \\
\left(\mathrm{RS} \times 10^{6}\right)^{*}\end{array}$ & $\%$ & $\begin{array}{c}\text { Salário } \\
\left(\mathrm{RS} \times 10^{6}\right)^{*}\end{array}$ & $\%$ & $\begin{array}{c}\text { ICMS } \\
\left(\mathrm{RS} \times 10^{6}\right)^{*}\end{array}$ & $\%$ \\
\hline$\overline{\text { Agricultura }}$ & 890,09 & 0,40 & 0,07 & 1,38 & 209,76 & 0,69 & 24,71 & 0,16 \\
\hline Mineração & 16518,53 & 7,41 & 0,08 & 1,58 & 848,53 & 2,80 & 239,84 & 1,56 \\
\hline Metalsiderúrgico & 17836,19 & 8,01 & 0,08 & 1,52 & 329,97 & 1,09 & 79,83 & 0,52 \\
\hline Maquinário & 1066,77 & 0,48 & 0,09 & 1,81 & 728,88 & 2,41 & 208,24 & 1,36 \\
\hline Florestal & 8340,26 & 3,74 & 0,14 & 2,66 & 981,71 & 3,24 & 153,48 & 1,00 \\
\hline Plástico & 1329,61 & 0,60 & 0,02 & 0,43 & 114,55 & 0,38 & 54,20 & 0,35 \\
\hline Petroquímico & 3156,09 & 1,42 & 0,04 & 0,78 & 386,50 & 1,28 & 1566,63 & 10,20 \\
\hline Têxteis & 2352,40 & 1,06 & 0,22 & 4,22 & 251,24 & 0,83 & 103,71 & 0,68 \\
\hline Alimentares & 6437,15 & 2,89 & 0,16 & 3,04 & 475,88 & 1,57 & 461,39 & 3,00 \\
\hline Diversos & 140,10 & 0,06 & 0,03 & 0,58 & 67,94 & 0,22 & 10,04 & 0,07 \\
\hline Serviços & 164717,18 & 73,94 & 4,27 & 82,00 & 25869,80 & 85,48 & 12459,52 & 81,11 \\
\hline Total & 222784,36 & 100,00 & 5,21 & 100,00 & 30264,77 & 100,00 & 15361,60 & 100,00 \\
\hline
\end{tabular}

*US\$1,00 = R \$1,81.

\section{CONCLUSÕES}

De acordo com os resultados deste estudo, concluise que:

- O setor florestal é importante para o desenvolvimento social e econômico do Estado do Espírito Santo, tanto na contribuição dos indicadores quanto dos multiplicadores de impacto da economia. Em geral, pode-se afirmar que o setor florestal está, em relação aos 11 setores, entre os quatro maiores na contribuição socioeconômica.

- No Estado do Espírito Santo, o setor florestal representa 5\% do valor da produção total capixaba e é responsável por 3,24\% das remunerações do estado e $8,13 \%$ das exportações, sendo o terceiro maior setor em superávit da balança comercial.

O setor florestal é todo voltado para o mercado internacional, apresentando baixa importação, pois consome matéria-prima produzida no mercado local, o que contribui expressivamente para o superávit da balança comercial do Estado.

R. Árvore, Viçosa-MG, v.29, n.1, p.105-113, 2005

\section{REFERÊNCIAS BIBLIOGRÁFICAS}

AGÊNCIA DE DESENVOLVIMENTO EM REDE DO ESPÍRITO SANTO. Apresentação. Disponível em: <http://www.aderes.com.br/ es_apresentacao.asp> Acesso em: 15 abril 2002.

CARVALHO, R. M. M. et al. O papel do setor florestal brasileiro no contexto nacional. In: CONGRESSO FLORESTAL BRASILEIRO, 8., 2003, São Paulo. Anais... São Paulo: SBS/SBEF, 2003. v. 2. CD-ROM.

HADDAD, P. R. Contabilidade social e economia regional: análise de insumoproduto. Rio de Janeiro: Zahar, 1976. 242 p.

INSTITUTO CAPIXABA DE PESQUISA, ASSISTÊNCIA TÉCNICA E EXTENSÃO RURAL INCAPER. Plano de desenvolvimento florestal do Estado do Espírito Santo. Disponível em: <http://www.incaper.es.gov.br/ florestal> Acesso em: 15 maio 2004. 
SACHS, J. D.; LARRAIN, F. B. Macroeconomia. São Paulo: Makron Books, 1998. 904 p.

SCHETTINO, L. F. et al. Diagnóstico para a gestão florestal sustentável no Espírito Santo. Revista Árvore, v.24, n.4, p.445-456, 2000.
SIQUEIRA, J. D. P. A administração das florestas. Disponível em: <http:// www.abimci.com.br/port/04Not/ 04FrameNot.html?Principal=04_020723AdmFlor.html> Acesso em: 15 setembro 2003. 
